\title{
V1 - ANÁLISE DA IMUNOGENICIDADE E GRAU DE PROTEÇÃO DE UMA VACINA INATIVADA PARA FEBRE AMARELA EM MODELO MURINO
}

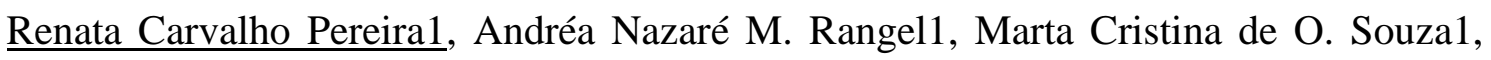
Marisol Simões1, Luciane P. Gaspar1, Elena Caride1, Ricardo Galler1

1Programa de Vacinas Virais, Instituto de Tecnologia em Imunobiológicos, Fundação Oswaldo Cruz, Rio de Janeiro, RJ 21045-900, Brazil.

\section{Objetivos}

Este trabalho teve como objetivo analisar a imunogenicidade e o grau de proteção em camundongos C57BL/6, de uma vacina inativada para febre amarela-cepa 17DD. O desenvolvimento desta nova abordagem vacinal, além de contemplar pessoas que residem ou viajam para áreas endêmicas, também pode ser administrada em pessoas nas quais a vacina atenuada é contraindicada.

\section{Metodologia}

A vacina foi desenvolvida a partir do cultivo de células Vero em biorreatores em meio livre de soro, purificada por cromatografia e inativada por agente químico. A análise da imunogenicidade e do nível de proteção foi realizada em camundongos C57BL/6 e a resposta imune humoral avaliada por PRNT, considerando o ponto de corte de 794 $\mathrm{mUI} / \mathrm{mL}$. Para o estabelecimento da melhor concentração de antígeno, os camundongos foram imunizados com três doses de $100 \mu \mathrm{l}$ da vacina inativada clarificada com 7.88 $\mu \mathrm{g} /$ dose, $3.94 \mu \mathrm{g} /$ dose ou $1.97 \mu \mathrm{g} /$ dose de proteína. Para a determinação do número mínimo de doses, os animais foram inoculados com uma, duas ou três doses da vacina inativada purificada, na concentração previamente estabelecida e na presença ou ausência do adjuvante hidróxido de alumínio. Os animais foram desafiados através da inoculação intracerebral de 100 DL50 do vírus 17DD. Para determinar o perfil isotípico das imunoglobulinas envolvidas na resposta humoral, foi realizado ELISA para subtipagem de IgG1 e IgG2a nos soros coletados 40 dias após a imunização. Foram considerados positivos soros com densidade óptica $(450 \mathrm{~nm})>0,3$. 


\section{Resultados}

Os resultados quanto ao estabelecimento da melhor concentração do antígeno demonstraram que, as três concentrações testadas foram capazes de induzir similarmente uma resposta mensurável de anticorpos neutralizantes, com concentrações de 3551 $\mathrm{mUI} / \mathrm{mL}$ (7.88 $\mu \mathrm{g} / \mathrm{dose}), 2496 \mathrm{mUI} / \mathrm{mL}$ (3.94 $\mu \mathrm{g} / \mathrm{dose})$ e $1901 \mathrm{mUI} / \mathrm{mL}(1.97 \mu \mathrm{g} / \mathrm{dose})$. Diante disto, optou-se por escolher a concentração de $2 \mu \mathrm{g} /$ dose da vacina inativada para darmos continuidade aos ensaios. Os resultados da determinação do número mínimo de doses indicaram que apenas os animais que receberam 3 doses da vacina inativada formulada com adjuvante apresentaram títulos de anticorpos neutralizantes acima do ponto de corte considerado positivo para febre amarela e taxa de sobrevivência de $100 \%$ após o desafio. Os resultados quanto à subtipagem destes anticorpos mostraram que todos os animais imunizados com a vacina inativada foram negativos para o isotipo $\operatorname{IgG} 2 \mathrm{a}$. No entanto, todos os animais foram positivos para o isotipo $\operatorname{IgG1}$, apresentando maiores concentrações nos grupos que receberam 3 doses da vacina inativada.

\section{Conclusões}

A imunização com três doses de $2 \mu \mathrm{g} /$ dose da vacina de vírus inativado contendo o adjuvante hidróxido de alumínio foi capaz de elicitar altos títulos de anticorpos neutralizantes, principalmente do isotipo IgG1. Além disto, protegeu $100 \%$ dos camundongos C57BL/6 após o desafio, apresentando perfil de proteção similar à vacina de vírus vivo atenuado administrada em dose única. 